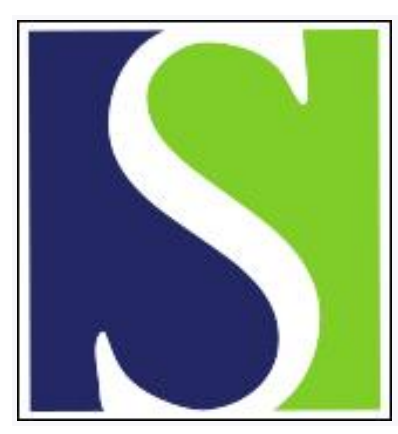

Scand J Work Environ Health 1996;22(6):444-450

https://doi.org/10.5271/sjweh.166

Issue date: Dec 1996

Incidence of lung cancer among cobalt-exposed women

by Tüchsen $F$, Jensen MV, Villadsen E, Lynge $E$

Key terms: cancer; cobalt-aluminate spinel; cohort study; epidemiology

This article in PubMed: www.ncbi.nlm.nih.gov/pubmed/9000312

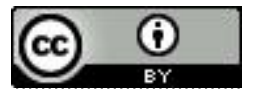




\title{
Incidence of lung cancer among cobalt-exposed women
}

\author{
by Finn Tüchsen, MSc, ${ }^{1}$ Marianne V Jensen, MD, ${ }^{1}$ Ebbe Villadsen, ${ }^{2}$ Elsebeth Lynge, PhD ${ }^{2}$
}

\begin{abstract}
Tüchsen F, Jensen MV, Villadsen E, Lynge E. Incidence of lung cancer among cobalt-exposed women. Scand J Work Environ Health 1996;22:444-50.

Objectives The purpose of this study was to estimate the risk of lung cancer for women occupationally exposed to cobalt-aluminate spinel.

Methods A retrospective cohort of 874 women occupationally exposed to cobalt in two Danish porcelain factories and 520 women not exposed to cobalt were identified from personnel files. Vital status was assessed in the national population register, and incident cancer cases were traced in the national cancer register. Thirteen women $(0.92 \%)$ were lost to follow-up. The observed deaths and incident cancer cases were compared with the expected number based on rates for all Danish women.

Results The total mortality of the cohort was the same as for all Danish women. The incidence of all cancer was slightly elevated among the exposed women (67 observed, 55.8 expected) and equal to the expected in the reference group (60 observed, 60.6 expected). An increased lung cancer incidence was found both in the exposed group [ 8 cases, standardized incidence rate (SIR) $2.35,95 \%$ confidence interval (95\% CI) 1.01 - 4.6] and in the reference group ( 7 cases, SIR $1.99,95 \%$ CI $0.8-4.1$ ). The exposed group had a relative risk ratio of 1.2 (95\% CI 0.4-3.8) when compared with the reference group.

Conclusions Both the cobalt-exposed group and the reference group had an increased lung cancer risk compared with all Danish women, but the risk was only slightly higher for the exposed group than for the reference group. The study was based on few persons, and we recommend a follow-up after five years.
\end{abstract}

Key terms cancer, cobalt-aluminate spinel, cohort study, epidemiology.

The evidence for a possible cancer risk associated with exposure to cobalt and cobalt compounds was reviewed (1) and evaluated (2) recently. In 1990 the International Agency for Research on Cancer concluded that the epidemiologic evidence was inadequate to classify cobalt or cobalt compounds as human carcinogens and that there was sufficient evidence for the carcinogenicity of cobalt metal powder and cobalt [II] oxide in experimental animals; limited evidence for metal alloys containing cobalt, chromium and molybdenum, cobalt [II] sulfide and cobalt [II] chloride; and inadequate evidence for cobaltaluminium-chromium spinel, cobalt [II,III] oxide, cobalt naphthenate, and cobalt[III] acetate (2).

Since then, an update of a French cohort study of workers employed in cobalt production in an electrochemical plant found a standardized mortality ratio of 0.85 [ 3 cases, $95 \%$ confidence interval $(95 \%$ CI) $0.18-$ 2.50] for lung cancer (3). As the original study was considered supportive of the hypothesis that cobalt expo- sure causes lung cancer, the update study weakened the evidence.

A recent study based on the Danish Product Register estimated that from 1964 to 1985 approximately 45000 workers had been exposed to cobalt in Denmark. They were employed in 136 companies and used a total of $100 \mathrm{t}$ of imported cobalt a year (4). A small amount was used in the production of hand-made underglaze porcelain plates.

The purpose of our study was to estimate the risk of cancer, especially lung cancer, among workers exposed to cobalt-aluminate spinel, the plate underglazing used in the porcelain factories in Denmark.

\section{Subjects and methods}

The study included all persons employed in the plate underglazing departments of two porcelain factories (fac-

1 National Institute of Occupational Health, Copenhagen, Denmark.

2 Danish Cancer Society, Copenhagen, Denmark.

Reprint requests to: Mr F Tüchsen, National Institute of Occupational Health, Lersø Parkallé 105, DK-2100 Copenhagen, Denmark. 
tory 1 and factory 2) in Copenhagen, Denmark, and a reference group from a cobalt-free department in factory 1 .

\section{Work description and work conditions}

The underglaze artware technique was developed in factory 1 in 1885 and first presented to the public at the World Fare Exposition in Paris in 1889. The plate production started in 1888 in factory 1 (5), and in 1895 in factory $2(6,7)$. The production of Christmas plates began in 1895 in factory 2 and in 1908 in factory 1, with regular series for collectors. Spray-painting equipment was available from the start of production.

In both factories, the underglaze workers were all located in one department. All workers performed the same work tasks, but the number of plates produced per day varied. The work process was as follows: The workers sprayed cobalt blue dye on bare plates (round, diameter $15-25 \mathrm{~cm}$ ) and later removed superfluous dye from parts of the plate in order to form a picture in white and various blue colors.

In both factories, an exhaust cupboard was built into the workplace of each worker. According to the memoirs of one of the first workers the exhaust cupboard was installed in 1904 in factory 1 . In factory 2 it was not installed in 1917-1919 according to photographs taken at the workplace. The exhaust cupboard had a dustpan at the bottom. In factory 1 the dustpan was filled with water. This pan was covered with foam rubber or felt (factory 1) or felt (factory 2). The cover was used to clean the rim of the plate, and the felt tip or wash leather was used to remove the dye. The cover itself was cleaned with compressed air, a process which seemed to be one of the main sources of exposure.

In factory 1 , both the spraying and the removing of dye were done in the exhaust cupboard. The plate was sprayed with water-containing dye. After the drying process, loose-fitting dye was removed with a brush. When the rim had been cleaned, by turning it upside down and rotating it on the rubber foam cover, the parts of the plate meant to be white or light blue were cleaned with a small brush or a piece of felt. The dye was sprayed on and removed three times. The exhaust cupboard had an opening that was $70 \mathrm{~cm}$ wide and of variable height, from 25 to $75 \mathrm{~cm}$. A sliding door could be used to reduce the opening, and thereby increase the airflow into the cupboard. In the opening the airflow had a minimum speed of $37 \mathrm{~m} \cdot \mathrm{min}^{-1}$.

In factory 2 the work process was performed in two workplaces. The dye was sprayed on the bare plates by a female worker holding an atomizer in a large fume extraction cupboard. After 1987 this cupboard was equipped with a permanent water film. After a pile of plates was sprayed and dried, it was carried to another workplace, where the superfluous dye was removed. The rim was cleaned on the felt cover. Superfluous color on the plate was removed with a piece of felt or with a wash leather. A brush was of no help in this department as the dye had a greater content of glue, and the plate had a deeper relief. The plates were then sprayed for the second time. The plate ended up with various blue shades and white parts. The removal of dye was performed at a desk with ventilation built into the front, and in an exhaust cupboard which was smaller than in factory 1 . At this workplace a small exhaust cupboard was placed on a table in front of each worker. The air speed was $85 \mathrm{~m} \cdot \mathrm{min}^{-1}$ in the exhaust cupboard doorway, and $60 \mathrm{~m} \cdot \mathrm{min}^{-1}$ in the dust pan in front of the exhaust cupboard. A few persons in the departments where cobalt was used were painting things other than plates, and their total exposure may have differed a little from that of the plate painters.

The reference group of women working in another department of factory 1 had no exposure to cobalt. They worked in a dust-protected room, where they decorated glazed porcelain with small paint brushes. The amount of paint used did not exceed $3 \mathrm{~g}$ a person per day. This reference group was chosen because of the small amount of dye used and because the porcelain was glazed before it was brought to the decoration department. Therefore it is unlikely that any significant exposure to carcinogens like asbestos or silica could have taken place.

\section{Exposure}

Over time, some important changes were made in the composition of the coloring agent. The exact years of changes were known only for factory 1. Quartz-based glazing was replaced by glass-based glazing in 1952 in factory 1 , and some years later in factory 2 . The two firms were amalgamated in 1987. In 1989, the workers from the underglaze departments of factory 2 moved to factory 1 , and the cobalt-aluminate spinel dye was then substituted by the cobalt silicate dye already used in factory 1 since 1972 . The cobalt content was approximately $25 \%$ in both kinds of dye. The content of nickel was less than $0.5 \%$.

Files of the National Institute of Occupational Health describe the work conditions and drawings of exhaust cupboards from 1948 and dust measurements from 1954. The concentration of dust was 170 particles $(0.5-$ $5 \mu) \cdot \mathrm{cm}^{-3}$ in 1954 and 150 particles in 1967.

In June 1981, the Industrial Health Center measured the airborne exposure to cobalt for 19 workers in factory 1. The hygienic standard was exceeded for all the workers in the range from 1.3 to 172 times. In addition, the hygienic standard for airborne total dust was exceeded in measurements for four workers. Levels of airborne exposure to cobalt silicate and urine excretion have been 
monitored regularly since 1982 in factory 1 and since 1989 in factory 2 (8). The concentrations of total dust and cobalt since 1981 are shown in figure 1.

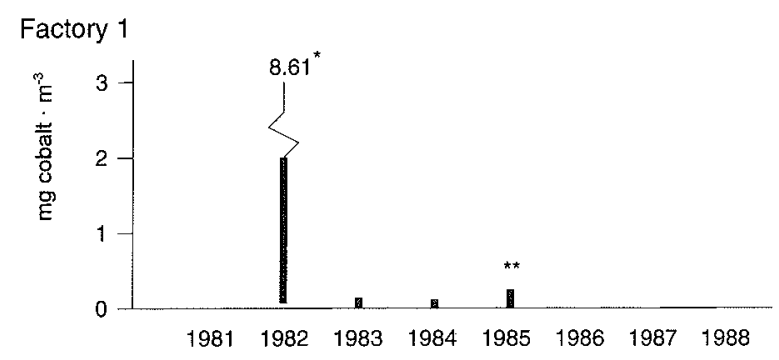

Factory 2

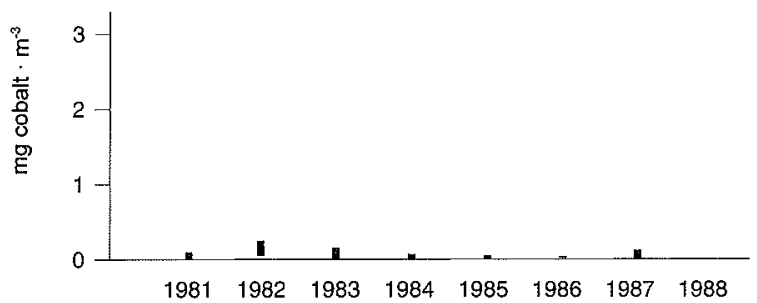

Factory 2

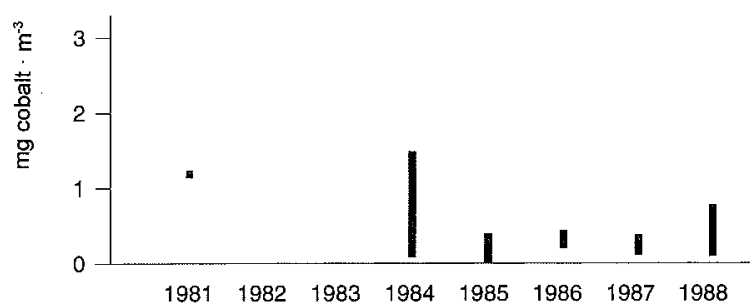

Figure 1. Concentrations of cobalt and total dust in samples from the underglaze departments of two Danish porcelain factories, 19811988. * Data taken from reference $9 ;{ }^{* *}$ one extremely high value, second highest value being $0.08 \mathrm{mg} \cdot \mathrm{m}^{-3}$.
As less attention was paid to exposures before 1980 , the levels may have been constant for many years before 1980. The main route of cobalt absorption in the plate underglazers was believed to be via the respiratory tract (2). The poor correlation between airborne exposure to cobalt-aluminate spinel and the urine excretion has, however, given rise to speculations about other routes of absorption (9). A recent study indicated that metallic cobalt from hard-metal grinding can penetrate the skin (10). It is not known whether the cobalt-aluminate spinel dye can penetrate the skin. Another study indicated that surface contamination might be a possible source of oral exposure (11). This may have been an alternative route of exposure, especially before 1982 when the plates were held in one hand during the spraying process. The forearm became almost as blue as the plates.

Throughout the century there was a cloakroom and a canteen for the workers, who were not allowed to smoke or drink coffee at the workplace. These rules were, however, frequently violated. All the workers were doing the same tasks with the same tools but personal habits, including productivity, may have caused different exposure levels (11). It was not possible, retrospectively, to classify the workers according to the number of plates produced or other personal characteristics.

\section{Study population}

We registered all the women employed at any time in the two underglaze porcelain plate departments. As a reference group we registered all female top glaze decorators employed in a department without cobalt exposure; see table 1. Altogether 1394 women were included in the study, 382 exposed from factory 1 and 492 from factory 2 together with 520 referents.

Table 1. Cohort admission criteria and the number of women employed in the underglaze and reference departments in two Danish porcelain factories and their vital status as of 31 December 1992.

First employment year included in the cohort Last employment year included in the cohort Last year of follow-up

Vital status

Alive 31 December 1992

Dead or disappeared before 1 January 1943

Dead between 1 January 1943 and 31 March 1968

Dead 1 April 1968 - 31 December 1992

Emigrated before + January 1943

Emigrated 1 January 1943 - 31 March 1968

Emigrated 1 April 1968 - 31 December 1992

Unidentified or lost to follow-up

Total

Persons included in the analysis

\begin{tabular}{|c|c|c|c|c|c|c|c|}
\hline \multicolumn{8}{|c|}{ Group } \\
\hline \multicolumn{2}{|c|}{$\begin{array}{l}\text { Exposed } \\
\text { factory } 1\end{array}$} & \multicolumn{2}{|c|}{$\begin{array}{l}\text { Exposed } \\
\text { factory } 2\end{array}$} & \multicolumn{2}{|c|}{ Referents } & \multicolumn{2}{|c|}{ All } \\
\hline Year & Number & Year & Number & Year & Number & Year & Number \\
\hline 1943 & . & 1962 & . & 1943 & . & varies & \\
\hline 1987 & . & 1987 & . & 1987 & . & 1987 & . \\
\hline 1992 & . & 1992 & . & 1992 & . & 1992 & . \\
\hline
\end{tabular}

a One person employed in 1962 in factory 2 , according to personnel files, emigrated before 1962 according to the population register. 
The cohort members were followed for death and emigration until the end of 1992 from data in the Central Population Register (available from 1968), and the municipality population registers.

Incident cancer cases diagnosed during the period from 1943 to 1992 were identified by linkage with the Danish Cancer Register. The period at risk was from 1 January 1943 (factory 1) or 1 January 1962 (factory 2) or date of first employment, whichever came last, until data of emigration, death or 31 December 1992, which ever came first.

A woman with employment periods in both the exposed and the unexposed (to cobalt) departments would be classified according to the first exposed employment period, and a woman with employment in both factory 1 and factory 2 was classified according to the first of these.

Cancer incidence rates for all Danish women for fiveyear age groups and five-year calendar periods were used for calculating the expected number of cancer cases (12). The PYRS program (13) was used for the calculation. We calculated $95 \%$ confidence intervals under the assumption that the observed number of cancer cases followed a Poisson distribution. The relative risk ratios and the $95 \%$ confidence intervals were calculated on the assumption of a binomial distribution estimated by a Poisson distribution (14).

\section{Results}

If cards from diseased persons had been removed from the personnel files, the results based on these files would be misleading. For factory 1 , the number of women registered in the personnel files could be compared with the number of women employed in the relevant departments according to various statistics from 1968 to 1987 . The figures corresponded well and therefore indicated that the cohort was complete.

For factory 2 , no statistics were available for comparison. Therefore, we checked the completeness of the files indirectly by comparing the observed number of deaths in the cohort with the expected number based on mortality rates for all Danish women. The overall mortality for all three groups corresponded well with the expected (table 2), and the cohort data were therefore unlikely to have an unbalanced deficit of registrations.

During the follow-up period, 127 cancer cases were diagnosed in the cohort (table 3 ). The overall cancer incidence was slightly elevated among the exposed women (observed 67, expected 55.80, SIR $1.20,95 \% \mathrm{CI}$ $0.94-1.52$ ), and close to unity in the reference group (observed 60, expected 60.62). There were 15 lung cancer cases. Two of the lung cancers observed (a solid squamous-cell lung carcinoma and a lung adenocarcinoma) were found in the same woman, but were, according

Table 2. Standardized mortality ratios for total mortality for the cobalt-exposed groups and for the reference group. Standard: all Danish women in the same calendar year.

\begin{tabular}{lcccc}
\hline Cohort segment & Number & $\begin{array}{c}\text { Observed } \\
\text { deaths } \\
(\mathrm{N})\end{array}$ & $\begin{array}{c}\text { Expected } \\
\text { deaths } \\
(\mathrm{N})\end{array}$ & $\begin{array}{c}\text { Standardized } \\
\text { mortality } \\
\text { ratio }\end{array}$ \\
\hline Exposed, factory 1 & 382 & 39 & 38.1 & 1.0 \\
Exposed, factory 2 & 492 & 28 & 25.4 & 1.1 \\
Reference & 520 & 91 & 96.3 & 1.0 \\
\hline
\end{tabular}

Table 3. Standardized incidence ratios (SIR) for all the cancer sites with at least one expected case (ICD-7 = 140-205) for the cobaltexposed groups and the reference group. Standard: all Danish women in the same calendar year.

\begin{tabular}{|c|c|c|c|c|c|c|c|c|c|c|c|c|}
\hline \multirow[t]{2}{*}{ Cancer site ${ }^{a}$} & \multicolumn{3}{|c|}{$\begin{array}{c}\text { All } \\
\text { exposed }\end{array}$} & \multicolumn{3}{|c|}{$\begin{array}{l}\text { Exposed, } \\
\text { factory } 1\end{array}$} & \multicolumn{3}{|c|}{$\begin{array}{l}\text { Exposed, } \\
\text { factory } 2\end{array}$} & \multicolumn{3}{|c|}{ Referents } \\
\hline & $\begin{array}{c}\text { Ob- } \\
\text { served }\end{array}$ & $\begin{array}{c}\text { Ex- } \\
\text { posed }\end{array}$ & SIR & $\begin{array}{c}\text { Ob- } \\
\text { served }\end{array}$ & $\begin{array}{c}\text { Ex- } \\
\text { posed }\end{array}$ & SIR & $\begin{array}{c}\text { Ob- } \\
\text { served }\end{array}$ & $\begin{array}{c}\text { Ex- } \\
\text { posed }\end{array}$ & SIR & $\begin{array}{c}\text { Ob- } \\
\text { served }\end{array}$ & $\begin{array}{c}\text { Ex- } \\
\text { posed }\end{array}$ & SIR \\
\hline Stomach (151) & 1 & 0.99 & 1.00 & 1 & 0.61 & 1.64 & - & 0.38 & - & 1 & 1.82 & 0.55 \\
\hline Colon (153) & 2 & 3.12 & 0.64 & 1 & 1.84 & 0.54 & 1 & 1.28 & 0.78 & 4 & 4.29 & 0.93 \\
\hline Rectum (154) & 2 & 1.52 & 1.32 & 2 & 0.90 & 2.22 & - & 0.62 & . & 1 & 2.19 & 0.46 \\
\hline Pancreas (157) & 2 & 0.97 & 2.06 & 1 & 0.58 & 1.72 & 1 & 0.39 & 2.55 & 1 & 1.36 & 0.74 \\
\hline Lung (162.0\& $\& 62.1)$ & 8 & 3.41 & $2.35^{b}$ & 3 & 1.87 & 1.60 & 5 & 1.54 & $3.25^{b}$ & 7 & 3.51 & 1.99 \\
\hline Breast (170) & 14 & 15.08 & 0.93 & 6 & 7.94 & 0.76 & 8 & 7.14 & 1.12 & 12 & 14.81 & 0.81 \\
\hline Cervis uteri (171) & 12 & 5.20 & $2.31^{\mathrm{b}}$ & 6 & 2.67 & 2.23 & 6 & 2.53 & 2.38 & 4 & 5.31 & 0.75 \\
\hline Corpus uteri (172) & 3 & 2.52 & 1.19 & 1 & 1.42 & 0.70 & 2 & 1.10 & 1.82 & 9 & 2.98 & $3.02^{b}$ \\
\hline Ovary (175) & 4 & 2.93 & 1.37 & 3 & 1.50 & 1.88 & 1 & 1.33 & 0.75 & 2 & 3.30 & 0.61 \\
\hline Kidney (180) & 1 & 0.99 & 1.00 & - & 0.57 & . & 1 & 0.42 & 2.38 & 1 & 1.22 & 0.82 \\
\hline Bladder (181) & - & 1.06 & . & - & 0.61 & . & - & 0.45 & . & - & 1.33 & . \\
\hline Melanoma (190) & 2 & 2.49 & 0.80 & - & 1.21 & . & 2 & 1.28 & 1.57 & 4 & 1.83 & 2.19 \\
\hline Other skin (191) & 8 & 6.00 & 1.33 & 5 & 3.22 & 1.55 & 3 & 2.78 & 1.08 & 5 & 6.05 & 0.83 \\
\hline Brain (193) & 1 & 1.99 & 0.50 & 1 & 1.02 & 0.98 & - & 0.97 & . & 3 & 1.78 & 1.68 \\
\hline Non-Hodgkin's lymphoma (200 \& 202) & - & 0.97 & $\cdot$ & - & 0.52 & . & - & 0.45 & . & - & 1.00 & \\
\hline Leukemia (204) & 2 & 0.94 & 2.13 & 2 & 0.52 & 3.86 & - & 0.42 & . & 3 & 1.09 & 2.75 \\
\hline All malignant neoplasms $(140-205)$ & 67 & 55.80 & 1.20 & 34 & 30.24 & 1.12 & 33 & 25.56 & 1.29 & 60 & 60.62 & 0.99 \\
\hline
\end{tabular}

a Code of the International Classification of Diseases, seventh revision, in parentheses.

b Lower limit of the $95 \%$ confidence interval above unity. 
to the cancer registration forms, independent cases diagnosed with several years' interval. The exposed women had a statistically significant increased risk of lung cancer (observed 8, expected 3.41, SIR 2.35, 95\% CI 1.014.62). An increased risk of lung cancer, although not statistically significant, was also found for the reference group (observed 7 , expected 3.51, SIR $1.99,95 \% \mathrm{CI}$ $0.80-4.11$ ). A comparison of the two exposed departments with the reference department gave a relative risk ratio of 1.2 (95\% CI $0.4-3.8)$. The only other cancer sites showing significantly elevated risks were cervical cancer among the exposed women (observed 12, expected 5.20, SIR 2.31, 95\% CI 1.19-4.03) and corpus uteri cancer in the reference group (observed 9, expected 2.98 , SIR $3.02,95 \%$ CI $1.38-5.73$ ).

\section{Discussion}

There is reason to believe that the biological response to cobalt and various cobalt compounds is complicated. One atom of cobalt is part of the essential vitamin $B_{12}$ (15). In the 1960s breweries in Canada, Belgium, and the United States added cobalt acetate(II), cobalt(II) chloride or cobalt sulfate to beer to reduce the foam, and occasionally deaths were observed from this cobalt exposure in heavy drinkers. Up to $50 \%$ of the deceased heavy beer drinkers died from doses much lower (up to $1.5 \mu \mathrm{g} \cdot \mathrm{ml}^{-1}$ beer) than the doses of cobalt(II) chloride hexahydrate used for treating anemia (oral doses of $20-300 \mathrm{mg}$ a day). It may thus be important to be specific about the chemical structure of the cobalt and confounding exposures. One implication of the change in factory 1 from cobalt-aluminate spinel to cobalt silicate in 1972 is therefore that the measurements of air and urine excretion are

Table 4. Percentage of smokers in the two Danish porcelain plants in 1982 (22) and 1987-1988 (23) and in the groups "all unskilled workers," "all skilled workers," and "all women" in Denmark (24).

\begin{tabular}{|c|c|c|c|c|}
\hline \multirow[t]{2}{*}{ Group } & \multicolumn{2}{|c|}{1982} & \multicolumn{2}{|c|}{$1987-1988$} \\
\hline & $\begin{array}{c}\text { Respon- } \\
\text { dents }\end{array}$ & Smokers & $\begin{array}{c}\text { Respon- } \\
\text { dents }\end{array}$ & $\begin{array}{c}\text { Smokers } \\
\%\end{array}$ \\
\hline Exposed, factory 1 & 49 & 69 & 25 & 50 \\
\hline Exposed, factory 2 & 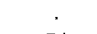 & & 36 & 31 \\
\hline Reference group |a & 51 & 29 & . & \\
\hline Reference group $\|^{\text {a }}$ & . & . & 48 & 46 \\
\hline Skilled women in Denmark & .. & 47 & & 55 \\
\hline Unskilled women in Denmark & .. & 55 & .. & 57 \\
\hline All Danish women ${ }^{D}$ & .. & 43 & .. & 42 \\
\hline
\end{tabular}

a Reference group I comprised workers from the same department as the reference group used in this study, while reference group II was from that department as well as from other departments in factory 2

- A cluster sample, stratified to be representative of all Danes, of approximately 20000 people are interviewed each year about their smoking habits. largely irrelevant for the estimation of exposures before 1972.

During the period from 1907 to 1972 only cobaltaluminate spinel was used in the production of plates. The cobalt oxide originated from Zaire, where it has been processed from a copper ore since 1907. The supplier has stated that traces of nickel, but no measurable contamination of nickel or arsenic was present. According to an analysis performed by the National Institute of Occupational Health, only insignificant amounts of nickel were present.

Sorbie et al (16) estimated the 24-h excretion of radioactive cobalt chloride from humans to be about $18 \%$. After absorption, the cobalt is mainly found in the liver (17). Eight days after administration, 56\% of the absorbed cobalt had been eliminated via the urine and $11 \%$ via the feces. After most cobalt chloride had been eliminated quickly, the remaining $10 \%$ usually clears slowly. The biological half-time is about two years $(18,19)$. It is thus likely that other organs may be at an increased cancer risk.

In our study 13 persons $(0.92 \%)$ could not be identified or were lost to follow-up. For at least one person, the index card was probably removed from the national files during World War II in order to protect members of the resistance movement and Jews. Three persons with temporary addresses had probably not registered. Others may have passed unnoticed due to a common name combined with an incorrect day of birth.

According to the memoirs of a former porcelain decorator, it was common for decorators to go for study visits to other factories in Europe. This may explain the high number of emigrated workers.

It is common that personnel files are selected in such a way that the records for persons known to be permanently ill are not included in new versions of the register, or they are even removed from existing files (20). If such a practice was used at these factories the true incidence would have been underestimated.

The total mortality in the three groups was near the average for "all Danish women." We have taken this finding as an affirmation of the completeness of the registration because missing records will almost certainly belong to diseased persons and consequently lead to an underestimation of the true risk.

We found a high lung cancer risk both in the exposed groups and in the reference group. The lung cancer incidence in female unskilled workers in the manufacturing sector in Denmark is known to be increased compared with that of all economically active women (relative risk 1.43) (21). Taking this into consideration, we are left with some indication of an increased risk of lung cancer for the cobalt-exposed workers, but the risk of the cobalt-exposed groups was only slightly higher than that of the reference group. 
Smoking is the major cause of lung cancer. We have only sporadic information on smoking habits in the studied population from two small surveys $(22,23)$. The response rate was $94 \%$ for the cobalt-exposed and $88 \%$ for the referents in 1982, while it was not known for the 1988 study. Smoking habits for the Danish population are known from annual surveys (24) (table 4).

There may have been more smokers in factory 1 than in the general population, but the differences per se, if any, are unlikely to explain the increased risk compared with that of all Danish women.

In one of the animal inhalation experiments on cobalt oxide tobacco smoke was used to increase the susceptibility of the animals (25). A similar synergistic effect in humans cannot be excluded. The latency time ranged from 10 to 43 years for the lung cancer cases from the exposed departments. One case had been exposed for $14 \mathrm{~d}$ only and two others for three to four months only. We found no association between length of employment and the incidence of lung cancer (data not shown).

A new composition of the dye was introduced in factory 1 in 1972 and in factory 2 in 1989. None of the lung cancer cases had worked with this new dye only. The number of workers hired for the first time after this change was small and the follow-up time was too short for the data to be conclusive.

We therefore recommend that this study be up-dated as soon as another set of five-year data is available on the incident lung cancer cases.

\section{Concluding remarks}

The incidence of lung cancer was increased among the workers exposed to cobalt-aluminate spinel, but the incidence was also increased among workers from the reference department. The study was based on few persons, and we recommend that it be up-dated as soon as cancer incidence data for an additional five-year period are available.

\section{Acknowledgments}

The authors wish to express their gratitude to Royal Copenhagen. The employer, the personnel manager and his staff, the workers, their health board, and the industrial health service are warmly thanked for their very active help, as are Miriam Holtzmann and Marianne Sattari for their contribution to this study.

This study was supported by the Danish Working Environment Fund, grant 1991-08, and the Danish Health Fund, grant H 11/108-91.

\section{References}

1. Jensen AA, Tüchsen F. Cobalt exposure and cancer risk. CRC Crit Rev Toxicol 1990;20:427 - 37.

2. International Agency for Research on Cancer (IARC). Chlorinated drinking water, chlorinated by-products; some other halogenated compounds; cobalt and cobalt compounds. Lyon: IARC, 1991. IARC monographs on the evaluation of carcinogenic risks to humans, vol 52.

3. Moulin JJ, Wild P, Fournier-Betz M, Mercier-Gallay M. A mortality study of cobalt production workers: an extension of the follow-up. Am J Ind Med 1993;23:281-8.

4. Hansen J, Schneider T, Olsen JH, Laursen B. Availability of data on humans potentially exposed to suspected carcinogens in the Danish working environment. Pharmacol Toxicol 1993;72 suppl 1:77-85.

5. Holmström S. Danske platter [Danish plates]. Århus (Denmark): Sesam, 1978.

6. The Royal Copenhagen Porcelain Manufactory. Plates. Copenhagen: Nordisk Forlag, 1970.

7. Granjean B. Den kongelige Porcelænsfabrik 1775-1975. [The Royal Porcelain Manufactory 1775-1975]. Copenhagen: Royal Copenhagen Porcelain Manufactory, 1975.

8. Christensen JM. Human exposure to toxic metals: factors influencing interpretation of biomonitoring results. Copenhagen: Arbejdstilsynet, 1995.

9. Christensen JM, Mikkelsen S. Cobalt concentration in whole blood and urine from pottery plate painters exposed to cobalt paint. In: Lekkas TD, editor. Proceedings of an international conference, heavy metals in the environment, Athens, September 1985; vol 2. Luxemburg: Commission of the European Communities, $86-8$.

10. Scansetti G, Botta GC, Spinelli P, Reviglione L, Ponzetti C. Absorption and excretion of cobalt in the hard metal industry. Sci Total Environ 1994;150:141-4.

11. Poulsen OM, Olsen E, Christensen JM, Vinzent P, Petersen $\mathrm{OH}$. Geltape method for measurement of work related surface contamination with cobalt containing dust: correlation between surface contamination and airborne exposure. Occup Environ Health 1995;52:827-33.

12. Storm HH, Manders T, Friis S, Bang S. Cancer incidence in Denmark 1989. Copenhagen: Danish Cancer Society, 1992.

13. Coleman M, Douglas A, Hermon C, Peto J. Cohort study analyses with a Fortran computer program. Int J Epidemiol 1986;15:134-7.

14. Gardner MJ, Altman DG. Statistics with confidence - confidence intervals and statistical guidelines. London: $\mathrm{Br}$ Med J 1992.

15. Svartengren M, Elinder C-G. Cobalt and its compounds. In: Zenz C, Dickerson OB, Howadt EP Jr, editors. Occupational medicine. St Louis (MO): Mosby, 1994:453-7.

16. Sorbie J, Olatunbotun D, Corbett WEN, Valberg LS. Cobalt excretion test for the assessment of body iron stores. Can Med Assoc J 1971; 104:777-82.

17. Comar CL, Davis GK. Cobalt metabolism studies, IV: tissue distribution of radioactive cobalt administration to rabbits, swine and young calves. J Biol Chem 1947;170:379-89.

18. Smith T, Edmonds CJ, Barnaby CF. Absorption and retention of cobalt in man by whole-body counting. Health Phys 1972; $22: 359-67$.

19. Newton D, Rundo J. The long term retention of inhaled cobalt-60. Health Phys 1970;21:377-_-84.

20. Lynge $\mathbf{E}$. Background and design of a Danish cohort study of 
workers in phenoxy herbicide manufacture. Am J Ind Med $1987 ; 11: 427-37$

21. Lynge E, Thygesen L. Occupational cancer in Denmark: cancer incidence in the 1970 census population. Scand J Work Environ Health 1990;16 suppl 2:1-35.

22. Raffn E, Mikkelsen S, Altman DG, Christensen JM, Groth S. Health effects due to occupational exposure to cobalt blue dye among plate painters in a porcelain factory in Denmark. Scand J Work Environ Health 1988;14:378 84.

23. Prescott E, Netterstrøm B, Faber J, Hegedüs L, Suadicani P, Christensen JM. Effect of occupational exposure to cobalt blue dyes on the thyroid volume and function of female plate painters. Scand J Work Environ Health 1992;18:101-4.

24. Nielsen PE, Zacho J, Olsen JA, Olsen CA. Endringer i danskernes rygevaner 1970-1987. Ugeskr Læger 1988;150: $2229-33$.

25. Wehner AP, Busch RH, Olson RJ, Craig DK. Chronic inhalation of cobalt oxide and cigarette smoke by hamsters. Am Int Hyg Assoc J 1977;38:338 46.

Recieved for publication: 8 January 1996 